\title{
Cooperation vs. Deliberation: Computer Medi- ated Conferencing and the Problem of Argument in International Distance Education
}

\author{
Michael Davis \\ Blekinge Institute of Technology, Sweden
}

Albert Rouzie

Ohio University, USA

\begin{abstract}
The idea that Internet-based distance education offers the potential to globalize higher education has not been matched by significant interest in the pedagogical and methodological issues at stake. This essay discusses a two-year experimental course conducted between two college classes in Karlskrona, Sweden and Ohio, in the United States. The goal of this course was to use online debate to augment intercultural understanding. This experiment involved both synchronous and asynchronous computer mediated conferencing (CMC) as well as various types of assignments intended to emphasize the discursive strengths of each $\mathrm{CMC}$ form. We discovered, however, that our assumptions about CMC discourse were challenged by the way it developed in our international contexts. Ultimately, we developed and propose a methodology that delimits and makes productive the playful agnostics of synchronous debate by employing asynchronous conferencing for the pre-debate development of common ground and the post-debate development of formal arguments.
\end{abstract}

\section{Key Terms:}

MOO, asynchronous conferencing, international education, collaboration, conflict, argumentation, American studies.

Globalization in higher education is more than "very distant" learning courses: it is a change in mindset.

Pat Maier

According to Donald E Hanna:

The marketplace for learning is becoming global. With new technologies, neither language nor distance is a barrier to access, although cultural norms and patterns are among the formidable obstacles to learning across political and cultural boundaries. (1998, p. 88) 
Cooperation vs. Deliberation: Computer Mediated Conferencing and the Problem of Argument in International Distance Education

This idea - that "networked learning has created a new flexibility in higher education's trans-national scope" (Trindade 2000, p. 20) - - has become somewhat of a cliche, but the potential for internationalization and cross cultural learning for distance education remains promising. However, if the promise seems far from being fulfilled, it is not merely a product of institutional resistance, as Pat Maier suggests. Guides to distance teaching might also be a part of the problem, which often lack fully developed pedagogies (Pallof \& Pratt 1999, p. 4; Garrison, 2000), and this, in turn, may reflect limitations on the current state of research. While studies have been published on the methodologies of teaching with specific information and communications technology (ICT) media (synchronous conferencing, asynchronous conferencing, hypertext, etc.), and using specific pedagogical techniques, few studies have been conducted on the ways in which various media can most effectively interact. Moreover, virtually all studies deal with local rather than international student bodies. Thus the methodologies they explore and pedagogies they develop have yet to show their applicability to international, intercultural education, precisely the kind of education that - as Hanna and the vast literature on intercultural communication reminds us - offers the greatest challenges to distance teaching.

In 1993 Diana Laurillard, Pro-Vice-Chancellor of Learning Technologies at the Open University, UK, argued that computer mediated conferencing (CMC) was incapable of addressing major steps of the learning process. Despite its age, her book remains one of the few theoretically grounded studies that attempted to prescribe specific combinations of media for specific distance teaching methodologies. ${ }^{1}$ According to Laurillard (1993, p. 170), CMC appears to help students develop a sense of shared experience, help students "refine their understanding" and, by means of collaborative tasks, potentially develop self-reflection (pp. 171173). However, it apparently does not lend itself to the generation or effective distribution of new knowledge (pp. 171-2). Most promoters of online conferencing would disagree, of course, claiming instead that the medium promotes the development of "critical thinking skills" (Paloff \& Pratt, 1999, p. 82) and/or learning through the sharing and debate of knowledge and experience (Paloff \& Pratt 1999 p. 83; Faigley 1992, p. 185). ${ }^{2}$ Nevertheless, doubts clearly remain about its efficacy (Palmquist 1998, pp. 212-215; Crook 1999, pp.106-109), and we are, as Jean and Geoffrey Underwood write, "just beginning to identify the components of effective [on-line] interaction," that "facilitate learning" (1999, p. 13).

If this is true, we have not even begun to understand how such "components" will function across the political and cultural borders that have so far limited our teaching and research. What follows is a narrative that aims to contribute to that beginning. 
Cooperation vs. Deliberation: Computer Mediated Conferencing and the

Problem of Argument in International Distance Education

\section{Background}

The examples discussed here are the product of a two-year experiment called Cultural Contact. The authors, ${ }^{3}$ one a North American rhetorician teaching in Sweden, and other a teacher and research who teaches composition in Ohio, conceived of it as an Internet-based forum between our courses using a varying set of Internet technologies. The two of us had become friends in graduate school, both having taught composition courses in computer classrooms. When Michael Davis got a job in Sweden and Albert Rouzie obtained an appointment in Ohio, we began discussing how we might use CMC technologies to bring our students together. We had both experienced the myopic ethnocentricity of college students in the US and now Michael Davis, in teaching an American culture course to Swedish students, discovered that even though his students knew a lot more about US culture than North American students knew about Swedish culture, their understanding was superficial and distorted by stereotypes. We saw CMC as a way to bridge our courses, as an opportunity to get students to learn about people in another culture, to reflect upon their own culture, and to provide them with experiences communicating with an audience with different assumptions. While Laurillard poses a conflict between the methodologies of online discussion and those of knowledge building, we assumed that there was no conflict, and that the goals of Cultural Contact neatly matched the social constructivism of our medium. CMC, we argued at the time, would "naturally" promote the movement from discussion to the generation of new knowledge.

Although the work of Wheeler and Shannon (1995) ought to have given us fair warning, our training and experience in computer-based composition pedagogy had still not prepared us for the logistical difficulties we encountered. In all but the most recent Cultural Contact sessions, Michael Davis's courses in Sweden were on American culture. The composition courses in Ohio focused on issues raised by the spread of the global economy: the downsizing and exportation of North American jobs, the ecological implications of the market economy, and other such issues. The class size in Sweden was large, making it impossible for all students in the course to be involved, necessitating the creation of an incentive to get enough student volunteers to participate in the month-long sessions. Swedish students who volunteered to participate in Cultural Contact sessions were allowed to substitute their work in Cultural Contact for some of the usually required work in the course. All of Albert Rouzie's 19 North American students participated as part of the course requirements for his section of firstyear rhetoric and composition. Access to computers and time in a computer classroom was greater for the Ohio class. A six- hour time difference made synchronous meetings difficult to schedule. ${ }^{4}$ To complicate matters, the term schedules between the two countries could not have been more different, causing the Swedes to participate in two Cultural Contact sessions to the North Americans' one.

Despite these obstacles, we became excited at the potential for cultural ex-

International Review of Research in Open and Distance Learning 
Cooperation vs. Deliberation: Computer Mediated Conferencing and the

change and engaged argument between groups with different assumptions. Both of us had been trained to teach composition through the argument structures of Stephen Toulmin, a modern day leader of rhetorical theory. Toulmin's approach asks writers to consider an array of elements in making successful arguments: particularly evidence, assumptions grounding the claim and evidence, and possible rebuttals and qualifications. From the outset, we viewed our goals as interrelated; like the instructor quoted in Knobel's "The Wired World of Second-Language Education" (1998, p. 39), we felt that cultural exchange and awareness could best be accomplished through rhetorical engagement of argument and that argumentation of sufficient depth would result in increased cultural sensitivity. We would, however, use Toulmin to structure this - as Faigley names it - "agonistic" discourse (1992, p. 185). Consequently for the first Cultural Contact session held during fall 1997, we created deliberative tasks (using an email listserv only) that would engage students in issues of interest to both groups.

\section{Cultural Contact 1: The Laurillard Paradigm}

This first session was successful only in terms of cultural exchange. Our students read short articles on censorship, comparative economic systems, and education, and then responded to prompts on each topic over a three-week period, one topic per week. ${ }^{5}$ Writing to each other extensively and personally from the start, students emailed messages to a discussion list, and the messages were archived on a Web page in chronological order. As an experiment in cultural exchange, the session was productive; students prompted each other for cultural information to such an extent that the assigned task was often ignored. While this kind of discursive decentering has long been championed as democratic and empowering to student groups usually silenced by the traditional classroom, the reasoned deliberation that, as Crosswhite reminds us, is one of the essential features of democratic discourse, was sorely missing (Faigley 1992, p. 182; Crosswhite 1996, p. 296). Any debate about student sent "information" was minimal; few topics generated a thread of more than two messages and little more than a superficial level of agreement (or, for that matter, disagreement). Faigely has argued that CMC tends to either Bruffean collaboration or Lyotardian agonistics (1992, p. 185). We got neither one nor the other.

In one of the threads with the most messages addressing "gender equality," we can see one of the common ways in which students responded to each other: 6

\section{Student X:}

Here in Sweden there is a general opinion that we have reached far dealing with gender equality. My opinion, though, is that we haven't come far enough. One way this problem has been dealt with is by 
Cooperation vs. Deliberation: Computer Mediated Conferencing and the Problem of Argument in International Distance Education

allocation of quotas by sex which in certain cases have been a good thing. But, for me this doesn't mean equality between the sexes. The question weather to give someone a job or not should be based on the skills and knowledge that person has, not on what sex he or she has. Instead of trying to make women work in areas that are male dominated - or vice versa - there should be more emphasis on men's and women's differences. It's better to look for balance in companies, governments etc. by finding what women do best and men do best and take things from there.

\section{Student Y:}

I am responding to the message I received on gender equality. I feel that when a person is applying for a job it should be based on skills and qualifications only!!! In the US they say that women have equal rights but when it comes to executive jobs or any job that has a lot of power it usually goes to a man. A woman could be more qualified and have a lot more experience than a man for the position but all that matters to them is the gender of the applicant. I think men are afraid of what might happen if women start gaining more control in the US. I think a lot of them are still old fashioned and feel that a womans place is in the home, not out in the work force. I feel that women should be able to obtain the equal rights that are given to them in the constitution.

There are two key discursive elements here that deserve emphasis. First, while this exchange represents a kind of adjacency pair, and the response demonstrates explicit linking strategy ("I am responding to."), the reasoning of the response contains no explicit linking. Consequently, it is difficult to see that student Y is expressing disagreement with student $\mathrm{X}$ about both the definition of gender equality and the legal means of improving it. Each message displays a relatively, if informally, well-developed chain of reasoning with what Toulmin logic defines as claims, reasons and assumptions. However, because the response avoids links that would create direct, discursive confrontation, the exchange does not lead into anything that could be called collaboration or argument. We named the pattern "associational disagreement," and it was nearly endemic for the session.

Some critics have argued that this pattern is typical of CMC on the whole (Mann, 2000, p. 185). However, we believed the failure of our students to engage each other was perhaps more likely to relate to our choice and methodological application of CMC technologies. Laurillard writes, "meaning is given through structure... For students to interpret a complex discourse they must be able to apprehend the implicit structure of that discourse" (1993, p. 51). In the following session, we therefore decided to move toward more formalized argument with, as Hawisher and Pemberton recommend, explicit requirements for 
Cooperation vs. Deliberation: Computer Mediated Conferencing and the

exchange (1998, p. 32). We also decided to move the Cultural Contact sessions to a technology that would emphasize this structure: newsgroup style asynchronous conferencing, in which the threads are organized into message trees. If graphically threaded asynchronous conferencing emphasizes discursive structure (i.e., linking) and, in turn, the development of "meaning," it ought to heighten the level of discursive interaction. Working from the agonistic paradigm of online discourse, which assumes that argument is its "natural" form, we assumed that the second Cultural Contact sessions would result in more, well-developed debate. We would, unfortunately, find ourselves disappointed.

\section{Cultural Contact 2: Emphasizing Structure}

The technology we chose for the second session of Cultural Contact was a Lotus Notes Domino Discussion forum, which functions essentially as a Web-based newsgroup open only to subscribers. We broke the classes into smaller groups so that the discussions would suffer less sprawl, and we assigned tasks that explicitly demanded reference to Toulmin log. The results, however, were frustrating. Although the graphical interface clearly displayed the threads for both ourselves and our students, (see Figure 1.) the level of direct exchange remained disappointingly low. Despite our efforts to recommend times for the posting of messages, students tended to concentrate their work onto the days they came to campus (in one case, Tuesdays and Thursdays). Consequently, there was little time for the development of long threads and thus "deeper" analysis. Similarly, as messages can be added to any node in a thread at any later date, students often failed to follow the development of a particular debate. Hence, most threads reached no more than six messages, and the few that did tended to show shortlived, intensive activity. An example of this can be seen in Figure 1., in which we find virtually all the thread's messages to have been posted between February 17 and 20. Furthermore, the forum interface posed some obstacles to the utilization and interpretation of the discursive structure, which lead to a tremendous number of misplaced or unthreaded responses. In fact, the longest "thread" (63 messages) was found under, what Domino called, "Not Categorized." In other words, potential exchanges were disrupted by lost messages.

Figure 1. Threaded Message Structure for Cultural Contact 2.

The few developed exchanges did show somewhat clearer displays of direct exchange. However, most exchanges avoided them. Instead, these exchanges showed an almost devious tendency to avoid the Toulminesque expectations of the discussion prompts and to focus instead on the mutually supportive sharing of information. What follows is an example. We posted two prompts:

\section{Prompts:}

International Review of Research in Open and Distance Learning 
Cooperation vs. Deliberation: Computer Mediated Conferencing and the

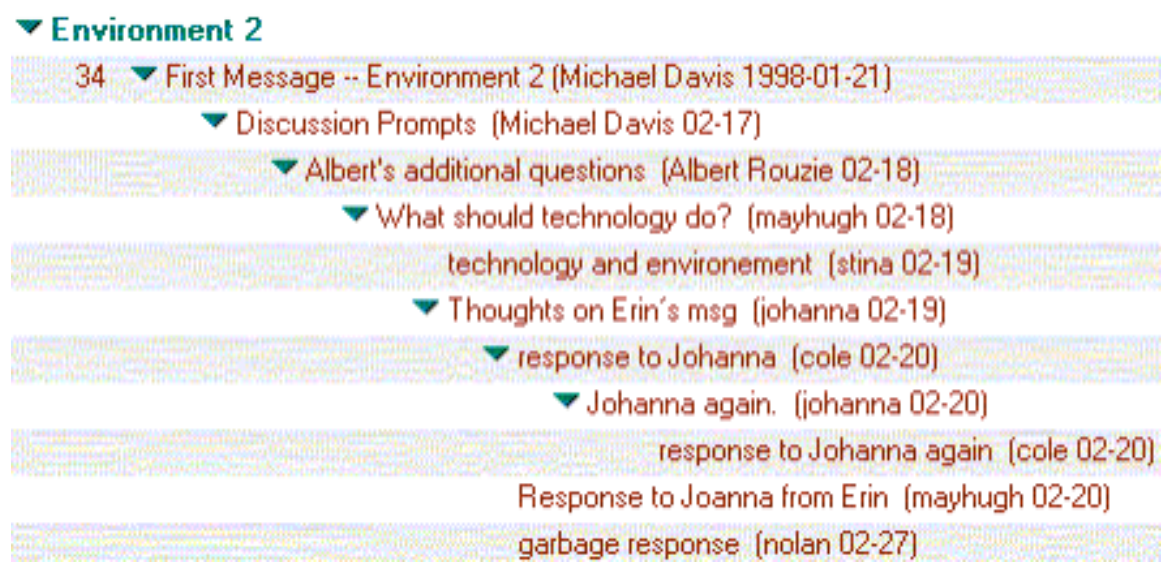

The authors are particularly down on "technology" and its chances of solving our global environmental problems. Do you agree with their argumentation? Are there sections of reasoning that you don't buy due to lack of support or hyperbolic reasoning? Can you think of counter examples or counter reasons?

The authors spend a lot of time attacking "moderate" proposals for dealing with global environmental problems, but never get around to giving us any practical alternatives (i.e. examples). Why? Can you give some? In what ways would your proposals effect our relationships to the global market? What problems might they set up for the article's argument?

Here is an excerpt of one of the exchanges:

\section{Student X:}

[Student X] here. I just like to say that I do agree with you Erin, that we can't repair all the damages already done but that technlolgy can help in the process of rebuilding and repair parts of the environment.. I also would like to say that I think people here in Sweden are really good on chosing environmental friendly products. We have several brands only making product that somehow spare the milieu some waste compared to the same products of other brands. Which is good. One thing that bothers me is that very often the green products are much more expensive than the non-green products. And a very good start is also to assort the domestic garbage in enviromnental safe and un-safe piles or garbarge bins. Do you have a lot of this in America? 
Cooperation vs. Deliberation: Computer Mediated Conferencing and the

\section{Student $\mathbf{Y}$}

[Student X] Hi! This is [student Y] and I had to respond to your message. There are many products here in America that are friendly to the environment, but just like Sweden those are the products that cost the most. Prices are dropping slowly and someday environmentalfriendly products will be equal in price with other items. That is one of the problems with trying to change the environment, is the cost. Recycling has become quite popular and most homes are equipped with a recycling bin to place out when the trash pick-up comes weekly. Here at school we even have recycling containers allowing students to recycle pop cans, pizza boxes, and used computer paper. The main way that Americans help the environment is through recycling because it does not take excessive amounts of time.

\section{Student X}

Thank you [student $\mathrm{Y}$ ] for your response. It is good to know that people care abut the environment. But I am afraid that the domestic recycling garbage bins will follow the toys. With this I mean that after a while it won't be "fun" anymore. I know that the environmental issue will never die. It is a constant problem. I also think it is scary when people don't care what is going on in other countries! Do you have that problem, that Americans only bother about American environment?

\section{Student $\mathbf{Y}$}

[Student Y] I agree with you totally. The recycling bins first came out a couple of years ago and since then they have lost their recycling appeal. Americans think about their country first and other countries later. Since the United States is larger then Sweden the problems in the environment are concentrated in the U.S. It is harder for other countries pollution to directly effect the U.S. since it has farther to travel. What every country does probably directly effects Sweden and your country would be worried about other countries environmental concerns. The U.S. is a world leader and they have to set environmental standards and other countries will follow the U.S.'s lead.

This excerpted exchange does reveal significant direct responses. It also reveals that the students have balanced our general expectations for cultural exchange

International Review of Research in Open and Distance Learning 
Cooperation vs. Deliberation: Computer Mediated Conferencing and the

and the task-specific goals of developmental argument, with the students working out the problematics of a proposal for green consumerism through a process of collaborative knowledge creation. However, most students did not, which is probably why the first question of both prompts that focus far more explicitly on analyzing an argument's Toulmin logic, were by and large ignored by the students. Information sharing was the predominant concern. Moreover, while we cannot say that our students avoided disagreement completely, direct disagreement about their peers' claims and reasons was virtually non-existent. Instead, what we tended to see was the pattern that we also see above and which might be called, corroboration with qualification.

As the sessions progressed, it became clear that our two goals of cultural exchange and rhetorical argumentation, while seemingly well matched, were often in conflict. Frustrated by the lack of challenging claims and counter-claims in students' discourse, we decided to add a limited number of synchronous MOO sessions to the Cultural Contact schedule, a medium that would create a tighter discourse - more immediate and message-dense. Although MOO discourse turned out to be more challenging and, at times, "interinsultive" (George 1990, p. 47), the sheets-to-the-wind breeziness of the MOO sessions often worked against our goals. When sufficiently controlled, students argued effectively in ways that could serve as informal invention for further development in formal composition. The MOO sessions' real virtue, however, appeared to be in encouraging the somewhat reticent Swedish students to come out of their shells, dare disagreement and confront the infamous cultural arrogance, real or imagined, of the North Americans. This uncompromising boldness, which at first we fostered, ultimately worked against the cooperation we had hoped to promote. We had veered from one extreme to another, from cooperative agreement without challenges or conflict to polarizing confrontation. We wanted both but had hoped that neither would dominate. The question that confronted us seemed to be whether or not one CMC technology - synchronous or asynchronous conferencing — would enable that to happen.

\section{Cultural Contact 3: The Limitations of Asyn- chronicity}

In The Rhetoric of Reason, James Crosswhite (1996) argues that argumentation can be learned only through reasoned conflict - by questioning and challenging, and the need to formulate responses. Hoping that this immediacy would help foster precisely that kind of argumentative conflict, for the third Cultural Contact session we divided our students into two groups, as a comparative ex-

periment. Some Swedes and some North Americans would meet in a room in DaMOO ${ }^{7}$ while some would interact (also synchronously) in the Web forum. Both groups were given the same prompts on the values placed on possessions

International Review of Research in Open and Distance Learning 
Cooperation vs. Deliberation: Computer Mediated Conferencing and the

and the issue of the Americanization of Sweden. In the MOO, students could directly make and support claims about the issues, challenge each other's statements, and get a clearer sense of dialogue - the playful interactions with other's senses of humor and rhetorical styles. Gathered together they could feel each other's verbal presence. The session was peppered liberally with questions, and many of them were answered. In the Web forum, on the other hand, fewer questions were asked and many were left unanswered. For example, one Web forum participant posed some good questions on what can be done about materialism. She wrote:

I think that it is often so that the things that we believe are personal are in fact simply a product of a consumer society. What is your opinion about this, and if you agree than do you think that this will ever change?

She follows by asking what it would be like if the opposite were true, that people were judged positively for having few possessions. These are precisely the kind of questions we valued because they could lead to connecting personal with cultural and mass-mediated spheres. Unfortunately, they elicited no responses. Of course, the lack of any response to this provocative question may be explained by the logistical difficulties introduced by the Web forum interface.

Another example demonstrates that some Web forum messages did lead to productive discourse. One Swede wrote:

Shop till you drop, the motto of the new religion of the later half of the 20 iSUP $i$ th century. The main ways in which we judge each other today are how we dress (or rather what brands our clothes are) and where and how we live.

A North American replied:

I do not think you are totally right. I do not see anything wrong with wanting to spend your money if you earned it, why not enjoy life.

Others weighed in and the result was a compromise (suggesting common ground), that some kinds of spending is acceptable, while others exhibit shallow materialism. In this example, the Web forum appeared to allow students to elaborate and qualify their statements in ways that MOO writers often did not.

The MOO writers dealt with this same issue of consumerism and prejudice, but their style was more terse and confrontational. Because MOOs allow a

International Review of Research in Open and Distance Learning 
Cooperation vs. Deliberation: Computer Mediated Conferencing and the

nuance in the form of give and take between the interlocutors, the discourse is more impassioned and appears designed to elicit response to create a dramatic effect. Substantial content emerges over many messages and can be judged only from the standpoint of the whole. Swedes, many of whom are reticent, dislike conflict and think assertiveness is boorish, actually came out of their shells in the MOO. ${ }^{8}$ In the Web forum, on the other hand, the Swedes made claims and asked questions, but response was not assured, and the slow pace maintained the polite distance lacking in the MOO. The discourse was less dramatic and impassioned, but each message appeared to be more carefully thought out. More information was exchanged in the Web forum, but the MOO discussion was more argumentative. Obviously this tradeoff suggests that the two venues may be used to complement one another, that each fulfills a different function, and that using one or the other, brings out the risks and limitations of each venue.

Despite the high percentage of purely playful messages typical for an initial MOO session, our first session featured a number of threads and a smattering of claims and challenges on the American dream, the Swedish dream, marriage, and money. An off-task thread erupted about food, and there was a virtual Elvis sighting. By far the longest thread focused on marriage, American vs. Swedish style. Here is an example:

"Why do you americans have to get married so young? is that the american dream?"

This message catalyzed the thread into a bolder more risk-taking dialogue than the Web forum. Although Davis has noted a tendency among Swedes to avoid confrontation, we found this less evident in the MOO sessions because the give and take pace favors short messages that weigh in on an issue. The Swedish students demonstrated that they are capable of hurling barbed messages with the best of them. For example, one Swede exclaimed:

"America the hamburger country — not MY dream!"

Another brought up North Americans' ignorance of world geography:

"Americans hardly know where the US is situated, isn't that right, yankees?"

\section{The Nature of Online Discourse}

CMC has been commonly considered to be a crossbreed of oral and written discourses, both in terms of linguistic patterning (Davis \& Brewer, 1997) and 
Cooperation vs. Deliberation: Computer Mediated Conferencing and the Problem of Argument in International Distance Education

rhetorical relations (Ong, 1982). Oral discourse, positioned as it is within faceto-face contact, supposedly lends itself to dialogue rather than monologue, polarization rather than accommodation, and informal reasoning rather than formal reasoning. Written discourse lends itself, it is claimed, to the contrary, and virtual discourse falls somewhere between the two. Unfortunately, this nice binary tends to fall apart right around the issue of polarization and accommodation. The hostility we saw in our MOO transcripts form an extension to the perhaps overly discussed flaming "problem," that certain types of messages shut out participants and shut down shared, reasoned dialogue. Put generally, one can safely say that, in some circumstances, CMC seems to increase polarization and reduce the opportunities for finding common ground (Herring, 1996), while in other circumstances it seems to have the exact opposite effect (El-Shinnawy \& Vinze, 1998). The question is why.

To answer that question we need to step briefly away from the original oralwritten binary to another: the difference between conversation and argument. According to Connery:

In discussion outside of institutional parameters or established purposive conversation (business meetings and the like), conversation exists for its own sake and it proceeds freely, unregulated by either a success orientation or instrumental or rational efficiency. Participants interrupt, contradict, and digress. At the coffeehouse (or at the corner saloon), unlike a discussion list or a business meeting, one would not ordinarily turn to others and attempt to establish rules for discourse or to demand closure or consensus. (1997, p. 174)

Connery constructs a situation in which argument (rule-bound, purposive discussion) is firmly opposed to conversation (free, open-ended discussion). But conversation - like all speech acts - is always purposive (Austin, 1962) if not explicitly persuasive (Walton, 1992, pp. 81-3), and it is not rule free (Garfinkle, 1967; Heritage \& Atkinson, 1984). Moreover, as Douglas Walton reminds us, most argument occurs not under formal conditions (e.g., business meetings) but occurs informally within "everyday" conversation (Walton 1992, pp. 2, 28, 81). In other words, Connery erases the middle ground of informal argument. Is it not possible that what we are seeing in online discourse - particularly in the relatively unstructured format of MOOs — is not merely a crossbreed of "pure" forms but another example of a third form? Perhaps the tensions that we perceive in CMC and its failures to live up to our expectations of formal, reasoned argument are less a product of the argumentative requirements of our assignments and more a product of the "limitations" of informal argument itself.

As Clark and Brennan point out, the fundamental function of informal argument is the determining of mutually accepted "grounds," the discursive norms that enable conversation to develop and discourse communities to evolve. In the CMC world, we imply a similar claim when we argue that what might be termed

International Review of Research in Open and Distance Learning 
Cooperation vs. Deliberation: Computer Mediated Conferencing and the

anti-social behavioral issues crop up in online discourse largely because the participants do not know where they are, to whom they are really speaking, and what the conventions of the media are. The logical extension of that argument, therefore, should be that before informal argument can take place the grounds for conversation need to be formed and accepted by the participants. The imposition of discursive standards is not enough. The students in our MOOs and forums should to be given the space and time to discover the set of rhetorical relations in which they are to engage. ${ }^{9}$ In the international and cross-cultural context of Cultural Contact sessions, in which the discursive grounds are even less clear than they would be otherwise, this is probably an absolute necessity.

It might be that the non-confrontational messages that made up so much of the first Cultural Contact session and the prompts for cross-cultural information that "clogged" debate in the second set of sessions formed attempts at precisely that kind of discovery. ${ }^{10}$ It may be that before reasoned argument can develop to any great length, particularly in cross cultural distance education, CMC must be allowed to grow as in the first Cultural Contact session, through open-ended prompts and invitations to personal response. The best possible media for such an extended conversation is not the message-dense, time-restricted and ethereal world of MOO space, but the more message-sparse and open-ended world of the email listserv or perhaps the Web forum. If conversation is more open-ended than argument, as Connery argues, and if it is often less explicitly purposeful, then it is the asynchronous forum that could help the students build a ground, a "commonplace" for argument.

\section{Cultural Contact 4: Separating Conflict from Co- operation}

For the fourth and latest session of Cultural Contact held in fall 1998, we created a syllabus that concentrated all the argumentative tasks into the MOO. For example, we had groups of students research the environmental problems of specific countries, especially global warming, and held a mock Earth Summit in the MOO. The success of each country's proposals depended on the votes of other groups. We used the Web forum to post pre-debate assignments (i.e., brainstorming; generation of enthymemes) and post-debate assignments (i.e., incorporation of rebuttals into the enthymemes to create Toulmin outlines). The debate prompts provided structured, argumentative tasks, which demanded that students state enthymemes, identify their peer's assumptions, and respond to them. It is to these debates that we will now turn. This time the Web forum acted as a MOO resource and archive of debate analyses. Although students were encouraged to respond to each other's analyses via the forum, we saw little interactivity there. The MOO is where all the discursive action took place. Action is what we got. The results were a far more confrontational debate than

International Review of Research in Open and Distance Learning 
Cooperation vs. Deliberation: Computer Mediated Conferencing and the

we had seen before. Here is the opening section of one of the MOO transcripts: sajber_guest ("cyber" in Swedish) exclaims, "WE OWN THIS PLACE, SOD OFF!!!"

uninvited_guest exclaims, "you wish!"

zombies_guest says, "we are mean and hungry, we are going to eat you alive"

sajber_guest sets the tone by initiating a wave of anarchistic hostility mixed with playful exchanges, which persists at some level almost for the entirety of the MOO session. For example, over a hundred messages later, the following playful exchange develops:

Dan_and_Posse_guest says, "Swedes, You know just about as little about us as we know about you. We are not all fat, don't you watch baywatch? We all look like that."

Instructor asks, "Any rebuttals to the assumption that laws against victimless activities are unfair?"

erika_\&_co_guest says, "And you are all running in slow motion on the beach"

Although off-task, the above quote demonstrates a playful exchange confronting the Swedish stereotype of fat Americans. The instructor's call for a return to task remained unheeded. He made that call several times during the MOO conference, sometimes because the participants just were not interested in getting on task, and at other times, because the on task activities were simply buried beneath the welter of messages.

In subsequent MOO sessions some Swedes discovered their confrontational abilities. The Swedes clearly sought to outrage their peers in the following argument about the child custody rights of homosexuals. In the following excerpt fricansa_guest is a small group of Swedish students sharing a computer, Dan_and_Posse_guest is a North American group, as is traceygroup_guest. First the enthymeme is shaped:

fricansa_guest says, "our enthymeme is that homosexuals shouldn't have children"

International Review of Research in Open and Distance Learning 
Cooperation vs. Deliberation: Computer Mediated Conferencing and the Problem of Argument in International Distance Education

Instructor says, "remember that the claim should claim that something is or is not cool or just. Please phrase your enthymemes that way. Also, include a reason, because . . . "

Dan_and_Posse_guest says, "Jazz is the best form of music because the musicians can actually PLAY their instruments"

fricansa_guest says, "BECAUSE it is not good for the kids"

fricansa_guest says, "the kids can get picked at if they live with two dads..."

Then, when they receive no responses, the following appears:

fricansa_guest says, "we have given the reason and now you are gonna here more...you say you are a christian country."

-...

fricansa_guest says, "why do u have a lot of gays and stuff"

$\cdots$

traceygroup_guest says, "we have religious choice, everyone is not christian"

fricansa_guest says, "we know but you have god on your bills and stuff"

$\cdots$

fricansa_guest says, "it is sick with gays"

Coming from students who live in a nation in which gay marriage was legalized almost without controversy and in which it is illegal to publicly threaten any minority group, such comments are dramatically inflammatory. That they are targeted at outraging the North Americans is also clear by the pronouns. The issue is not "us" but "you" people, the North Americans. It is interesting to note that both Frincasa_guest and the earlier discussed sajber_guest are female

International Review of Research in Open and Distance Learning 
Cooperation vs. Deliberation: Computer Mediated Conferencing and the

participants, suggesting that Herring's recent article on women's tendency to shy away from confrontation in online discourse certainly does not apply here. In our experience, the Swedish women were not pulling any punches. It is important to note that their initial reason for opposing gay marriage refers to possible negative effects on the children of such unions, a point that could be considered reasonable or at least arguable. However, they moved rather quickly from this reason to the expressed assumption that any Christian country should oppose gay marriage on moral grounds as "sick." Although we have no clear rationalization for the gender issues at stake, we do have some for the cultural issues. Despite Dan_and_Posse_guest's claim ("Swedes, You know just about as little about us as we know about you"), Swedes actually have the upper hand when it comes to such contests because they know so much more about North American culture than North Americans do about Sweden's. The cultural dynamics that led the Swedes to use their superior knowledge to exert dominance are complex, suggesting some degree of resentment by the Swedes against the cultural hegemony of the US. The unfortunate result was that the interest in cultural sharing nearly disappeared from this Cultural Contact session, and an important but perhaps undervalued discursive method for building up a shared set of references was lost.

Despite these problems, argument did take place, even if one has to untangle it from the jumble of barbs and cross-wires. What we have seen is that one or two well-developed threads can be expected from an entire online discussion, no matter the medium. These latest MOO sessions can reveal great improvement, depending on the way in which the instructor manages the participants. However there are trade-offs. The particularly hostile frincasa_guest transcript saw nearly a hundred messages before the instructor took charge of the discourse, and all topics were dealt with simultaneously. The participants posted their enthymemes and then challenged their peers' postings as they saw fit. The chaos of the session is largely to blame for this limitation, simply because the swirl of "extraneous" messages prevented concentrated exchange or extended development. In contrast, the less hostile session held simultaneously in another MOO "room" resulted in much longer threads, because the instructor imposed a discussion time-table early in the session so that one topic would be dealt with at a time. Students lost the discursive freedom that the other instructor provided and which some see as the ideological justification for online discourse. One student even went so far as to call the instructor a "dictator."

The length of the threads is not everything, of course, and in both threads the more structured prompt clearly resulted in a greater focus on argumentation. Students clearly practiced formulating enthymemes, successfully identifying unstated assumptions and attacking them. They also engaged in what might be termed "MOO forensics." A thread on marijuana, for example, revealed reasonable argumentative depth, with the dialogical development pattern of rebuttal and counter-rebuttal going through nine exchanges. In each case, the argumentative goals of the assignment were met to a certain degree, and we experienced

International Review of Research in Open and Distance Learning 
Cooperation vs. Deliberation: Computer Mediated Conferencing and the Problem of Argument in International Distance Education

a much greater degree of argumentative intensity and development. By those standards, the MOO conferences should be considered a success, particularly if we do not expect online deliberation to go beyond the depth of informal argument.

As mentioned earlier, while we asked students to respond to each other's MOO argument analyses, they tended not to. Consequently, the essays they ultimately produced rarely discussed their peer's analyses. Moreover, as the analyses were almost universally less agonistic and more conciliatory then the MOO transcripts, the essays generally emphasized student disagreements and differences. Argument had overwhelmed any process of cooperation. We concluded that an analysis of a MOO conflict's logic should not be an end, but rather a means to an educational relationship; the recognition of discord's depth should not form final "commonplaces." We nervously chuckle at one of us being called a dictator, in part because we do not want that to be the memory that lives after us as teachers. We ought to similarly be made uncomfortable by the thought that the memory, which lives after a forum like Cultural Contact session is not a coalescence, but a separation, a series of ruptures rather than the collaborative art of bridge building.

We realized that we must give our students a methodology for transforming the discovery of a logical problem's depth into the beginning of that problem's solution, to move from conflict analysis to conflict mediation. The commonplace created through this process would be truly shared by the participants, a common-ground formed by their attempts at what Michael Gilbert (1997) calls "coalescent argumentation."

In Artificial Morality, Peter Danielson proposes that ethical societies - groups that interact cooperatively - can derive from within the assumptions of evolutionary game theory. As he summarizes his argument, "social evolution can be trusted to solve some difficult social dilemmas if some participants can constrain themselves, identify other' cooperative dispositions, and use them to discriminate whose behaviors they accept" (1996, p. 72). While some of this process can be recognized in our enthymeme-analysis assignment, much cannot. This is, in part, because the assignment failed to impart a cooperative goal for the analysis of assumptions. Rather the students sought to merely challenge and question them. As Crosswhite convincingly argues, such tasks are necessary for the proposer of claims, if she is going to gain a better understanding of the foundations, strengths, and weakness of her position. However, a more constructive pedagogy would want to transform argumentative confrontations into the grounds for cooperation. If such a transformation is to be based on a principle of gradual, social evolution, we think it is fair to ask if the MOO is the right medium of CMC.

We want to propose that the ultimate function of Cultural Contact CMC should be to radically emphasize "practical reasoning," the choosing of a course of action on the basis of one's rhetorical situation (Gilbert, 1997, p. 210). Moreover,

International Review of Research in Open and Distance Learning 
Cooperation vs. Deliberation: Computer Mediated Conferencing and the

its goal should not merely be the discovery of tensions and differences, but a move toward conflict resolution. Such a process would place MOO confrontational discourse at its center, but would place asynchronous forum discourse on either side as a means for the evolution of cooperative grounds on the one side, and a means for less cooperatively intended arguments on the other. In this way, we might utilize the strengths of both venues and find the most constructive balance for the goals of Cultural Contact: practicing argumentation informed by cross cultural understanding and cross cultural understanding informed by argumentation.

\section{Conclusion}

To take this a step further, we need to imagine more clearly how an assignment could use asynchronous and synchronous forums for conflict and cooperation. Over the course of our four Cultural Contact sessions, we found our students most responsive to culturally oriented readings, assignments, and discussion prompts. A cultural orientation need not preclude controversial issues such as assisted suicide, the death penalty, gay rights, censorship of extremist ideas and pornography, socialized medicine, and so on, since, in our case, the two countries' policies and attitudes on these issues are so different. But for both cooperative and conflictual rhetoric to prevail, the assignment needs to explicitly require give and take. Students on each side must depend on the communication of information and arguments from the other to be able to deliver on their project.

To this point the greatest success we experienced in this regard centered on the analysis of North American and Swedish magazine ads. We used both of our course Web sites to post digitally scanned magazine ads, some chosen by Swedes, some by Americans, and used the Web forum for the posting of assigned ad analyses. This led to two small group MOO sessions discussing how the ads work and the cultural differences between the American and Swedish ads. Some interesting differences emerged: In discussion of an American ad for vacation in Jamaica, typically devoid of anything particularly Jamaican, North Americans defended the ad's appeal to tourist hedonism, while some Swedes were critical of its assumption that tourists visit such countries only for fun in the sun. Some Swedish ads baffled Americans and vice-versa. An ad for a tortilla mix generated much discussion. The ad featured an image of thirty-something Swedish couples making the tortillas together at a party. The Swedish students had to explain why Swedes might find this appealing, and this led to a discussion of gender roles (a man cooks the tortillas). Similarly, a multi-page Nike ad that exhibited nude athletes caused confusion among the Swedes when it was not readily apparent what nudity had to do with the product being sold. A Swedish beer add presented a photo of the frozen northern Lapland, an image with considerable cultural resonance for Swedes that utterly befuddled the Ohioans who associate beer not with solitude, but with crowded parties and bars. The

International Review of Research in Open and Distance Learning 
Cooperation vs. Deliberation: Computer Mediated Conferencing and the

cultural differences and similarities brought out by analyzing and discussing the ads were surprising and yielded significant interchange.

Using this assignment as a starting point, we have begun to develop a more general methodology for the kind of international distance education that Cultural Contact promotes. The assignment has been revised to require that groups of North American students interview Swedish students (and vice versa) about the cultural assumptions (denotative and connotative levels) of consumer advertising. To emphasize its cooperative and social-evolutionary function, we match the task with a simple asynchronous discussion forum. We then ask students to debate issues that we find there in the $\mathrm{MOO}$, thus encouraging the students to explore and challenge their differences. The transcripts are then posted to the forum for study. To develop and formalize the level of understanding and argumentation, the students then write analyses that compare the ways in which the two cultures' employ and react to the ads, based on specific cultural assumptions they discovered in the interviews and debates. These essays are posted to the forum, and finally, to promote their coalescent function, we ask the students to respond to their peer's work, as well as the online learning process as a whole, using, once again, the discussion forum. By alternating between asynchronous and synchronous CMC technologies in this way, we utilize them for their most appropriate discursive ends. By encapsulating the synchronous within the asynchronous, we attempt to set up and intercultural collaboration and deliberative agonistics toward a greater understanding of each other's culture, as well as their own.

If successful - and our most recent experiments hint that it will be - this pattern of encapsulation and alternation can provide an important model for computer-assisted distance education in the humanities, one that recognizes the complexity of our students' relations to online discourse, as well as the global, discursive environment in which they increasingly act. 
Cooperation vs. Deliberation: Computer Mediated Conferencing and the

Problem of Argument in International Distance Education

\section{References}

Atkinson, J.M. \& Heritage J. (Eds.). (1984). Structures of Social Action: Studies in Conversation Analysis. Cambridge: Cambridge University Press.

Austin, J.L. How to Do Things With Words. (1962). Cambridge, Mass: Harvard University Press.

Clark, Herbert H. \& Brennan, Susan E. (1991). "Grounding in Communication." In Perspectives on Socially Shared Cognition.

Lauren B. Resnick, John M. Levine, \& Stephanie D. Teasley (Eds.) p. 127-149. Washington, DC: American Psychological Association.

Connery, Brian A. (1997). "IMHO: Authority and Egalitarian Rhetoric in the Virtual Coffeehouse." In David Porter (Ed.). Internet Culture. p. 161-180. London: Routledge.

Crook, Charles. (1999). "Computers in the Community of Classrooms." In Karen Littleton and Paul Light (Eds.). Learning with Computers: Analysing Productive Intereaction. p. 102-117. London: Routledge.

Crosswhite, James. (1996). The Rhetoric of Reason: Writing and the Attractions of Argument. Madison: The University of Wisconsin Press.

Danielson, Peter. (1992). Artificial Morality: virtuous robots for virtual games. London: Routledge.

Danielson, Peter. (1996). "Pseudonyms, Mailbots, and Virtual Letterheads." In Charles Ess (Ed.). Philosophical Perspectives in Computer-Mediated Communication. p. 67-94. Albany, NY: SUNY Press.

Davis, Boyd H. \& Jeutonne P. Brewer. (1997). Electronic Discourse: Linguistic Individuals in Virtual Space. Albany, NY: SUNY Press.

El-Shinnawy, Maha \& Ajay S. Vinze. (1998). "Polarization and Persuasive Argumentaiton: a Study of Decision-Making in Group Settings." MIS Quarterly 22.2: p. 165-99.

Faigley, Lester. (1992). Fragments of Rationality: Postmodernity and the Subject of Composition. Pittsburgh: University of Pittsburgh Press.

Garfinkel, H. (1967). Studies in Ethnomethodology. Englewood Cliffs, N.J.: Prentice-Hall.

Garrison, Randy. (2000). Theoretical Challenges for Distance Education in the 21 ¡SUP $i$ st Century: a Shift from Structural to Transactional Issues." International Review of Open and Distance Learning 1.1: p. 1-17. [Online] Available at: http://www.irrodl.org/v1.1.html.

International Review of Research in Open and Distance Learning 
Cooperation vs. Deliberation: Computer Mediated Conferencing and the

George, Laurie E. (1990). "Taking Women Professors Seriously: Female Authority in the Computerized Classroom." Computers and Composition 7: p. $45-52$.

Gilbert, Michael A. (1997). Coalescent Argumentation. Mahwah, NJ: Lawrence Erlbaum Publishers.

Hanna, Donald E. (1998). "Higher Education in an Era of Digital Competition: Emerging Organizational Models." Journal of Asynchronous Learning Networks 2.1: p. 66-95.

Hawisher, Gail E. \& Michael A Pemberton. (1998). "WAC Encounters Asynchronous Learning Networks." In Donna Reis, Dickie Self and Art Young (Eds.). Electronic Communication across the Curriculum. p. 17-40. Urbana: National Council of Teachers of English, 1998.

Haynes, Cynthia. (1998). "Help! There's a MOO in This Class!" In Cythia Haynes and Jan Rule Holmevik (Eds). High Wired. p. 161-176. Ann Arbor: Michigan University Press.

Heritage, J. \& Atkinson J.M. "Introduction." Atkinson and Heritage. p. 1-15.

Herring, Susan. (1996). "Posting in a Different Voice: Gender and Ethics in CMC." In Charles Ess (Ed.) Philosophical Perspectives in ComputerMediated Communication. p. 115-146. Albany: SUNY Press.

Knobel, Michele, Colin Lankshear, Eileen Honan, \& Jane Crawford. (1998). "The Wired World of Second-Language Education." In Ilana Snyder (Ed.). Page to Screen: Taking Literacy into the Electronic Era. p. 20-50. NY: Routledge.

Laurillard, Diana. (1993). Rethinking University Teaching: a Framework for the Effective Use of Educational Technology. Routledge: London.

Mann, Chris \& Fiona Stewart. (2000). Internet Communication and Qualitative Research: a handbook for Researching Online. London: Sage Publications.

Ong, Walter. (1982). Orality and Literacy: The Technologizing of the Word. London: Methuen.

Pallof, Rena M. \& Keith Pratt. (1999). Building Learning Communities in Cyberspace: Effective Strategies for the Online Classroom. San Francisco: Jossey-Bass Publishers.

Palmquist, Mike, Kate Keifer, James Hartvigsen, \& Barabara Goodlew. (1998). Transitions: Teaching Writing in Computer-Supported and Traditional Classrooms. Greenwich, Connecticut: Ablex Publishing Corporation.

Shannon, Linda K. (1998). "International E-mail Debate." In Donna Reiss, 
Cooperation vs. Deliberation: Computer Mediated Conferencing and the

Dickie Selfe and Art Young (Eds.). Electronic Communication Across the Curriculum. p. 151-161. Urbana: National Council of Teachers of English.

Sweden. (1986). The Swedish Immigration Board. Sweden: a general introduction for immigrants. Norrköping: The Swedish Immigration Board.

Trindade, Armando Rocha, Hermano Carmo \& José Bidarra (2000). "Current Developments and Best Practice in Open and Distance Learning." International Review of Research in Open and Distance Learning 1.1: p. 1-25. [Online] Available at: http://www.irrodl.org/v1.1.html.

Underwood, Jean \& Geoffrey Underwood. (1999). "Task Effects on Collaborative Learning." In Karen Littleton and Paul Light (Eds.). Learning with Computers: Analysing Productive Intereaction. p. 10-24. London: Routledge.

Walton, Douglas N. (1992). Plausible Argument in Everyday Conversation. Albany, NY: SUNY Press.

Wheeler, C. Bradley, Joseph S. Valacich, Maryam Alavi, \& Doug Vogel. (1995). "A Framework for Technology-mediated Inter-institutional Telelearning Relationships." JCMC 1.1. [Online] Retrieved Oct 1, 2001: http://www.ascusc .org/jcmc/vol1/issue1/index.html. 
Cooperation vs. Deliberation: Computer Mediated Conferencing and the

Problem of Argument in International Distance Education

\section{Endnotes}

1. Laurillard herself claims that her analysis "is not a prescriptive process."

Rather it "suggests which media [each discursive process] should be combine with" (1993, p. 176). This distinction is, to say the least, unclear.

2. Composition and language teachers also emphasize the importance of the medium's effect on the development of writing skills. See, for example, Shannon (1998, p. 154) and Palmquist (1998, p. 125).

3. The names have been temporarily replaced with asterisks to maintain anonymity for purposes of publication review.

4. Pallof and Pratt emphasize the problems of time zone in their discussion of international distance education (1999, p. 46). In the context of the other scheduling, institutional and educational clashes, time-of-the-day scheduling was perhaps the easiest to resolve.

5. Here is an example of an early Cultural Contact discussion prompt:

The United States is very tolerant of violence on broadcast television, while Sweden is not. Sweden, on the other hand, allows soft-core erotic movies to be shown on broadcast television, while the United States does not. Which nation has it right? Why? Support your claims with reasons, examples and, perhaps, warrants.

6. Spelling appears exactly as in the transcripts. Some messages have been deleted, signaled by an ellipsis.

7. DaMOO is an educational MOO operated out of California State University at Northridge. For further information, see their Web site at: [http://damoo.csun.edu/. ]

8. As Sweden: a General Introduction to Immigrants reassuringly reads, "You will notice that Swedes do not readily show their feelings, but this does not mean they have none" (Sweden, 1986, p. 13).

9. This point is emphasized by researchers in MOO pedagogy (ex. Haynes and Holmevik, 1998, pp. 161-176).

10. The second set of sessions involved the same class or Swedes but two separate classes of North Americans.

International Review of Research in Open and Distance Learning 
Cooperation vs. Deliberation: Computer Mediated Conferencing and the Problem of Argument in International Distance Education

\section{Citation Format}

Davis, Michael \& Rouzie, Albert (April, 2002) Cooperation vs. Deliberation: Computer

Mediated Conferencing and the Problem of Argument in International Distance Education.

International Review of Research in Open and Distance Learning: 3, 1.

http://www.icaap.org/iuicode?149.3.1.x 